ARTICLE

https://doi.org/10.1038/s41467-019-09826-2

\title{
A gas-plastic elastomer that quickly self-heals damage with the aid of $\mathrm{CO}_{2}$ gas
}

Yohei Miwa (1) ${ }^{1}$, Kenjiro Taira ${ }^{1}$, Junosuke Kurachi ${ }^{1}$, Taro Udagawa $\mathbb{D}^{1}{ }^{1}$ \& Shoichi Kutsumizu ${ }^{1}$

Self-healing materials are highly desirable because they allow products to maintain their performance. Typical stimuli used for self-healing are heat and light, despite being unsuitable for materials used in certain products as heat can damage other components, and light cannot reach materials located within a product or device. To address these issues, here we show a gas-plastic elastomer with an ionically crosslinked silicone network that quickly selfheals damage in the presence of $\mathrm{CO}_{2}$ gas at normal pressures and room temperature. While a strong elastomer generally exhibits slow self-healing properties, $\mathrm{CO}_{2}$ effectively softened ionic crosslinks in the proposed elastomer, and network rearrangement was promoted. Consequently, self-healing was dramatically accelerated by $\sim 10$-fold. Moreover, self-healing was achieved even at $-20^{\circ} \mathrm{C}$ in the presence of $\mathrm{CO}_{2}$ and the original mechanical strength was quickly re-established during the exchange of $\mathrm{CO}_{2}$ with air.

\footnotetext{
${ }^{1}$ Department of Chemistry and Biomolecular Science, Faculty of Engineering, Gifu University, Yanagido, Gifu 501-1193, Japan. Correspondence and requests for materials should be addressed to Y.M. (email: y_miwa@gifu-u.ac.jp)
} 
$\mathrm{N}$ ature produces a multitude of elegant dynamic networks that perform specific functions, such as self-healing, excellent fatigue and fracture resistance, and ultrastretchability. For example, the dynamic crosslink properties of actin filaments in cytoskeletal networks demonstrate certain cell activities, such as adaption and migration of cells ${ }^{1,2}$. Another example is spider silk, where, upon external loading, densely assembled hydrogen bonds in the silk repeatedly deform and reform to effectively dissipate energy, avoiding the concentration of local stresses that trigger fractures ${ }^{3,4}$. The concept of dynamic networks has the potential to play an important role in improving safety, energy efficiency, mechanical toughness, and the lifetime of human-made products ${ }^{5}$. In particular, self-healing materials that perform at ambient temperatures are exceptionally useful for specific types of futuristic high-performance products, such as artificial skin, soft robots, wearable sensors and PCs, and smart actuators, which will have the capability to maintain their performance for humans in daily life ${ }^{6-8}$.

Dynamic networks autonomically self-heal at room temperature in cases where flexible polymers with low glass transition temperatures $\left(T_{\mathrm{g}}\right)$ are weakly crosslinked by dynamic bonds, such as hydrogen bonding ${ }^{9-15}$, metal-ligand coordination ${ }^{16-19}$, and ionic bonding ${ }^{20-23}$, even without the application of healing agents or the input of external energy. However, these materials often present a trade-off between strength and their autonomous self-healing rate, i.e., self-healing materials that respond quickly are generally viscoelastic and exhibit low tensile strength, often even far below 1 $\mathrm{MPa}$. In contrast, thermally or optically reversible bonds and interactions display rapid self-healing characteristics while maintaining a high degree of strength ${ }^{24-35}$. However, heat and light, which are the most commonly used stimuli for self-healing, are unsuitable for materials used in certain products because heat can potentially damage other components, and light is not applicable if those materials are located inside the product.

To address these issues, a dynamic network that quickly self-heals damage at ambient temperature with the aid of $\mathrm{CO}_{2}$ gas is presented. The ionically crosslinked poly(dimethyl siloxane) (PDMS) elastomer described in this paper exhibited high strength $(\sim 3.5 \mathrm{MPa})$ in air, though the rearrangement of the network was dramatically accelerated by $\mathrm{CO}_{2}$ gas, which effectively softens the material's crosslinking sites, such as the ionic aggregates (Fig. 1a, c). This results in rapid self-healing in $\mathrm{CO}_{2}$ gas atmosphere at normal pressures $(\sim 0.1 \mathrm{MPa})$ (Fig. 1d). Notably, the original mechanical strength was quickly re-established in the exchange of $\mathrm{CO}_{2}$ with air (Fig. 2b); i.e., the proposed material is the gas-plastic elastomer, which makes it particularly useful in the development of self-healing materials because the gas is able to permeate components inside the product, and the exposure of most products to $\mathrm{CO}_{2}$ gas would not result in damage to other components. Our gas-plastic elastomer is based on this conceptual design.

\section{Results}

Material design. We synthesized an oligomeric PDMS, which has $\mathrm{COOH}$ groups at the ends of the chain and at middle positions placed randomly along the backbone; the $\mathrm{COOH}$ groups are partially neutralized with sodium (Fig. 1a and Supplementary Fig. 1). PDMS was chosen as a backbone because of its flexibility, biocompatibility, and high $\mathrm{CO}_{2}$ permeability ${ }^{36}$. In this case, lowmolecular-weight PDMS is suitable because self-healing of the dynamic network is accomplished via chain diffusion of constituent polymers. The number average molecular weight and a

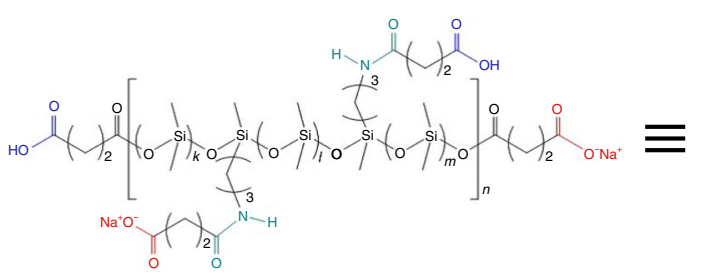

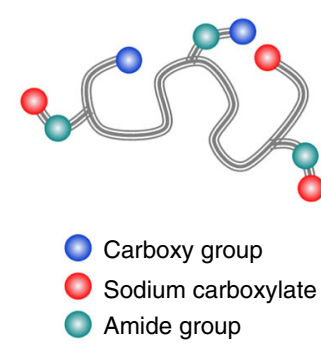

b

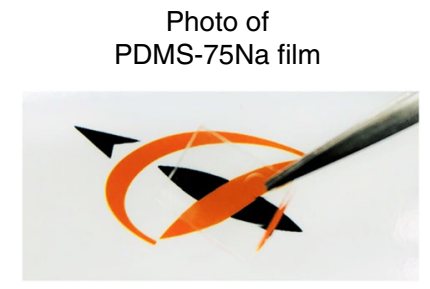

C

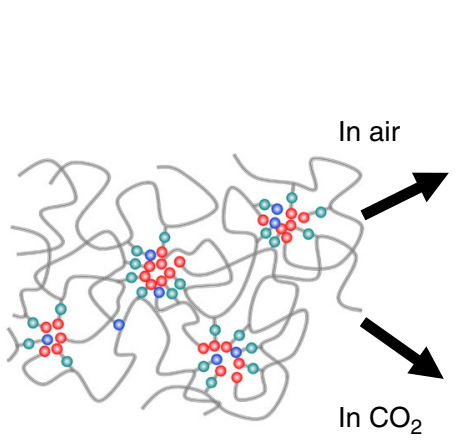

Slow rearrangement
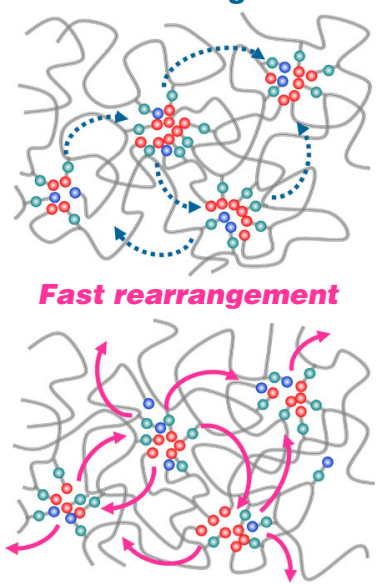

d 


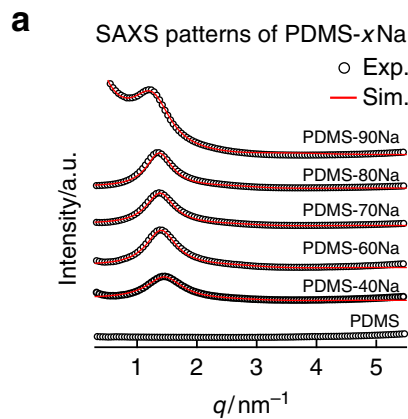

C

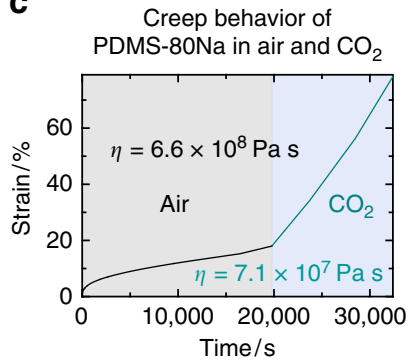

b

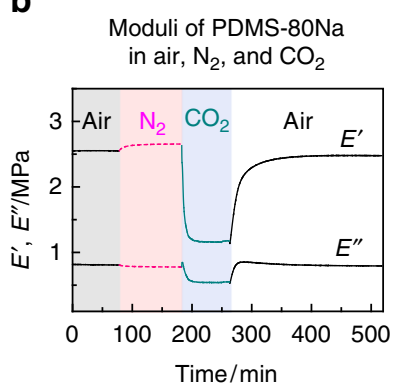

d

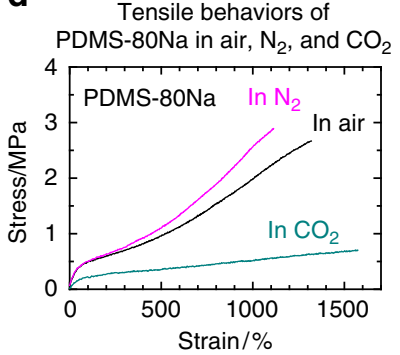

Fig. 2 Effect of $\mathrm{CO}_{2}$ on mechanical properties of PDMS-80Na. a Experimental and simulated SAXS patterns for PDMS- $x \mathrm{Na}$. $\mathbf{b}$ Effect of each gas on the storage modulus $\left(E^{\prime}\right)$ and loss modulus ( $\left.E^{\prime \prime}\right)$ for PDMS$80 \mathrm{Na}$ measured at $1 \mathrm{~Hz}$ and $30^{\circ} \mathrm{C}$. c Creep test for PDMS-80Na measured at a stress of $4 \mathrm{kPa}$ at $30^{\circ} \mathrm{C}$. Air flow is changed to $\mathrm{CO}_{2}$ gas flow. d Tensile tests for PDMS-80Na measured at $27 \pm 1^{\circ} \mathrm{C}$ in air, in $\mathrm{N}_{2}$, and in $\mathrm{CO}_{2}$. The stretching speed is $100 \mathrm{~mm} \mathrm{~min}^{-1}$

the molecular weight distribution of the PDMS are 7300 and 1.56, respectively. However, a decrease in the molecular weight tends to result in the display of weak and viscoelastic properties in the particular material. Therefore, the ends of the chain were capped with an ionic group to restrict their mobility and thereby reduce this tendency. The total $\mathrm{COOH}$ concentration was determined to be $3.8 \mathrm{~mol} \%$ by titration, and $40-90 \%$ of the $\mathrm{COOH}$ groups were neutralized with sodium hydrate. The unneutralized and neutralized PDMSs are denoted as PDMS-COOH and PDMS- $x \mathrm{Na}$, respectively, where $x$ indicates the percentage of neutralization. These materials were characterized by gel permeation chromatography, ${ }^{1} \mathrm{H}-\mathrm{NMR}$ (Supplementary Fig. 2), and Fouriertransform infrared spectroscopy (FT-IR) (Supplementary Fig. 3). The PDMS- $x$ Na film is completely colorless and highly transparent (Fig. 1b).

The size of the ionic aggregates acting as physical crosslinks in PDMS- $x \mathrm{Na}$ was determined by the simulation of small-angle $\mathrm{X}$ ray scattering (SAXS) pattern based on the Yarusso-Cooper model $^{37}$ (Fig. 2a). In this model, spherical-shaped ionic aggregates with a radius of $R_{1}$ are randomly dispersed subject to the closest approach limitation, $2 R_{\mathrm{CA}} . R_{1}(1.2 \mathrm{~nm}), R_{\mathrm{CA}}(2.0$ $\mathrm{nm})$, and the number density $\left(24(10 \mathrm{~nm})^{-3}\right)$ of the ionic aggregates in PDMS- $x \mathrm{Na}$ are virtually independent of the level of neutralization, except for PDMS-90Na (Supplementary Fig. 4). This suggests that most of the neutralized and unneutralized $\mathrm{COOH}$ groups are involved in ionic aggregates irrespective of the level of neutralization. When the $T_{\mathrm{g}}$ of backbone polymers is far below room temperature, the neutralized and unneutralized $\mathrm{COOH}$ groups dynamically hop between ionic aggregates at room temperature; $23,38,39$ in other words, the network is considered to be dynamic. The hopping rate is determined based on the balance between the backbone polymer flexibility (mobility) and the attractive force between the crosslinking sites. Fast rearrangement of ionic crosslinks results in rapid self-healing, although it is also the cause of weak and viscoelastic material properties. PDMS

$\left(T_{\mathrm{g}} \approx-120^{\circ} \mathrm{C}\right.$ ) is significantly flexible polymer (Supplementary Fig. 5). Therefore, not only ionic groups, but also hydrogenbonding amide groups were additionally introduced to enhance the attractive force between crosslinking sites in our designed PDMS- $x \mathrm{Na}$ (Fig. 1a). The interaction energy of the hydrogen bonding between the amide groups was determined to be -78.7 $\mathrm{kJ} \mathrm{mol}^{-1}$ based on density functional theory calculations, where the energy between sodium carboxylates was found to be $-190 \mathrm{~kJ}$ mol $^{-1}$ (Supplementary Fig. 6).

Mechanical properties. In contrast to other network systems crosslinked by weak and dynamic bonds, such as hydrogen bonding $^{9-15}$ and metal-ligand coordination ${ }^{16-19}$, the rearrangement rate of ionic crosslinks is easily tunable by altering the neutralization level. The relaxation temperature assigned to the network rearrangement in the PDMS- $x \mathrm{Na}$ decreased as the neutralization level decreased (Supplementary Fig. 7). Namely, the rearrangement rate of ionic crosslinks in PDMS- $x \mathrm{Na}$ at room temperature increased as the neutralization level decreased because unneutralized carboxy groups act as plasticizers in the ionic aggregates ${ }^{39}$.

The rearrangement of ionic crosslinks simultaneously performs several important mechanical functions. It enhances the fracture resistance due to the detachment of stressed chains, and therefore toughens the elastomer, while it also enhances the fatigue resistance and autonomic self-healing properties at room temperature without the input of energy (e.g., heat or light). Due to the rearrangement of the ionic crosslinks, the strength and stretchability of PDMS- $x \mathrm{Na}$ severely depend on the neutralization level and the stretching speed (Supplementary Fig. 8). For example, when the neutralization level is high $(80 \%)$, a high degree of fracture stress $(\sim 3.5 \mathrm{MPa})$ is displayed for stretching at $300 \mathrm{~mm} \mathrm{~min}^{-1}$. On the other hand, very high stretchability $(\sim 12,000 \%)$ is achieved for a relatively low neutralization level $(40 \%)$ at $10 \mathrm{~mm} \mathrm{~min}^{-1}$, while a very high neutralization rate $(90 \%)$ produces a brittle film. For oligomeric PDMS with very high neutralization level, intramolecular aggregation of ionic groups is probably enhanced and crosslinking polymer chains between ionic aggregates are decreased, thereby yielding brittle PDMS-90Na.

Gas-plastic properties. The PDMS- $x$ Na presented in this study actually exhibited gas-plastic properties. For example, in $\mathrm{CO}_{2}$ gas atmosphere at normal pressures, the storage modulus $\left(E^{\prime}\right)$ of PDMS-80Na dropped steeply to less than half of that in air, while it slightly increased in $\mathrm{N}_{2}$ gas (Fig. $2 \mathrm{~b}$ ), which indicated that the $\mathrm{CO}_{2}$ gas softened the material. On the other hand, the $E^{\prime}$ quickly recovered as a result of the exchange of $\mathrm{CO}_{2}$ with air. Moreover, when a stress of $4 \times 10^{3} \mathrm{~Pa}$ was applied to PDMS-80Na, the strain rate increased from $2.2 \%$ per hour in air to $20 \%$ per hour in $\mathrm{CO}_{2}$ (Fig. 2c). At the same time, the fracture stress of PDMS-80Na decreased significantly from $2.7 \mathrm{MPa}$ in air to $0.7 \mathrm{MPa}$ in $\mathrm{CO}_{2}$ (Fig. 2d). Some polymers, including PDMS, exhibit $\mathrm{CO}_{2}$ gas plasticization $^{40-42}$. However, our PDMS- $x \mathrm{Na}$ elastomer exhibits more distinct $\mathrm{CO}_{2}$ gas plasticization. In fact, the moduli of commercially available chemically crosslinked PDMS elastomer displayed little change from the application of $\mathrm{CO}_{2}$ gas (Supplementary Fig. 9). Our results clearly demonstrated two important characteristics: (1) $\mathrm{CO}_{2}$ gas affects ionic domain and (2) high $\mathrm{CO}_{2}$ permeability of PDMS produces a rapid self-healing response. Notably, moisture also plasticizes PDMS-80Na; however, $\mathrm{CO}_{2}$ gas plasticizes PDMS-80Na more efficiently (Supplementary Fig. 10).

The FT-IR bands at $1586 \mathrm{~cm}^{-1}$ and $1716 \mathrm{~cm}^{-1}$ assigned to the stretching vibrations of sodium carboxylate and carboxy groups, respectively, are affected by $\mathrm{CO}_{2}$ exposure (Fig. 3a). This demonstrates that the $\mathrm{CO}_{2}$ molecules having relatively high polarizability penetrate into the ionic aggregates, leading to the 
FT-IR spectra of PDMS-80Na in air and $\mathrm{CO}_{2}$

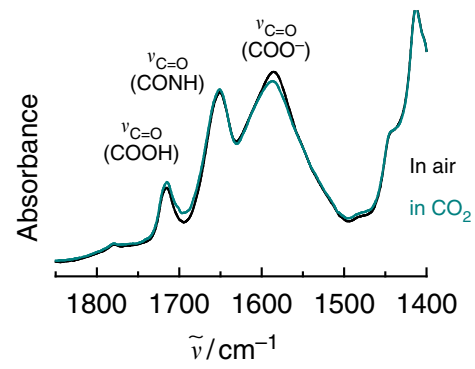

C

Network rearrangement behaviors in PDMS-80Na in air and $\mathrm{CO}_{2}$

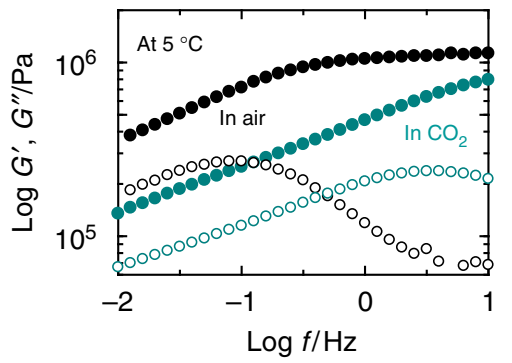

b Local $T_{\mathrm{g}}$ of ionic aggregate in PDMS-80Na in each gas

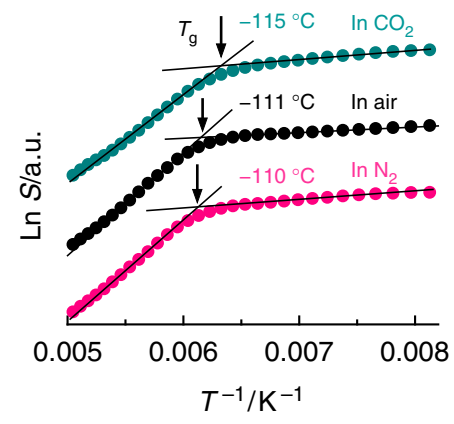

d

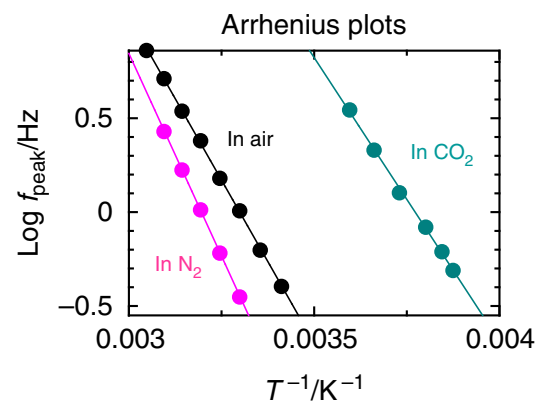

Fig. 3 Effect of $\mathrm{CO}_{2}$ on ionic aggregate and network rearrangement. a FT-IR spectra of PDMS-80Na measured in air and in $\mathrm{CO}_{2}$. b Temperature dependence of the saturation factor $(S)$ for PDMS-80Na in air, $\mathrm{N}_{2}$, and $\mathrm{CO}_{2}$. The inflection temperature represents the local $T_{\mathrm{g}}$ of ionic aggregate. c Frequency sweep of storage modulus ( $G^{\prime}$, solid symbols) and loss modulus ( $G^{\prime \prime}$, open symbols) for PDMS-80Na measured at $5^{\circ} \mathrm{C}$ in air and in $\mathrm{CO}_{2}$. The relaxation is assigned to rearrangement of ionic crosslinks. d Arrhenius plots of peak frequency of $\mathrm{G}^{\prime \prime}$ for $\mathrm{PDMS}-80 \mathrm{Na}$ in air, in $\mathrm{N}_{2}$, and in $\mathrm{CO}_{2}$

plasticization of the ionic aggregates. The plasticization of ionic aggregates by $\mathrm{CO}_{2}$ gas was directly confirmed via an electron spin resonance (ESR) technique reported by Miwa et al. ${ }^{43}$. When using this method, the local $T_{\mathrm{g}}$ of the ionic aggregates in the PDMS- $x \mathrm{Na}$ is selectively measured by ESR using a spin probe localized in the ionic aggregates, and here, 4-carboxy-TEMPO was used (Supplementary Fig. 11). The location of the spin probe in the ionic aggregates was confirmed from one of the magnetic parameters of nitroxide, $A_{\mathrm{zz}}$, which increased with increasing local polarity. The large $A_{\mathrm{zz}}$ value of 34.7 Gauss was evidence of 4-carboxy-TEMPO located in the ionic aggregates of PDMS- $80 \mathrm{Na}^{43}$. In $\mathrm{CO}_{2}$, the local $T_{\mathrm{g}}$ of ionic aggregates in PDMS- $80 \mathrm{Na}$ decreased by $4{ }^{\circ} \mathrm{C}$ and $5^{\circ} \mathrm{C}$ compared with that in air and in $\mathrm{N}_{2}$, respectively (Fig. $3 \mathrm{~b}$ ). The plasticization of ionic aggregates resulted in an increase in the network rearrangement rate. In fact, the relaxation assigned to the network rearrangement in PDMS-80Na was distinctly accelerated in $\mathrm{CO}_{2}$ gas atmosphere, while the relaxation rate slowed slightly in $\mathrm{N}_{2}$, compared with that in air (Fig. 3c, d; Supplementary Fig. 12). The relaxation time, $\tau\left(=f_{\text {peak }}{ }^{-1}\right)$, of the network rearrangement at $25^{\circ} \mathrm{C}$ was determined to $1.6 \mathrm{~s}, 4.9 \mathrm{~s}$, and $0.055 \mathrm{~s}$ in air, in $\mathrm{N}_{2}$, and in $\mathrm{CO}_{2}$, respectively (Fig. 3d). The network rearrangement accelerated by approximately 30 times in the presence of $\mathrm{CO}_{2}$ gas compared with that in air.

Self-healing properties. PDMS- $x \mathrm{Na}$ exhibited autonomic selfhealing at room temperature. For example, when a cherry blossomshaped PDMS-75Na film was cut, placed in contact, and stored at room temperature, the cut pieces completely connected (Fig. 4a). The PDMS- $x \mathrm{Na}$ self-heals irrespective of the neutralization level (Supplementary Fig. 13). Under $\mathrm{CO}_{2}$ exposure, the self-healing quickly undergoes (Fig. 4b). The self-healing behavior of PDMS$80 \mathrm{Na}$ was accelerated by $\sim 10$ times in $\mathrm{CO}_{2}$ compared with that in air because of the accelerated network rearrangement (Fig. 4c), and healing was achieved even at $-20^{\circ} \mathrm{C}$ with a healing efficiency of $\sim 50 \%$ after 1 week (Fig. $4 \mathrm{~d}$ ). At $-10^{\circ} \mathrm{C}$, healing efficiencies of $\sim 50 \%$ and $\sim 90 \%$ were achieved after 3 days and 1 week, respectively. Unlike other self-healing materials that chemically consume $\mathrm{CO}_{2}$ gas, such as concrete ${ }^{44}$ and a hydrogel containing chloroplast ${ }^{45}$, our gas-plastic elastomer physically utilizes $\mathrm{CO}_{2}$ gas as a plasticizer. Therefore, this elastomer permanently demonstrates the rapid selfhealing induced by $\mathrm{CO}_{2}$ exposure.

\section{Discussion}

In this study, we developed a gas-plastic silicone elastomer that exhibits high mechanical strength and rapid self-healing with the aid of $\mathrm{CO}_{2}$ gas. The key aspect of the gas-plastic capability is the softening of the ionic aggregates that act as crosslinking sites in the elastomer owing to the effects of the $\mathrm{CO}_{2}$ gas. Importantly, the gas-plastic technique should be widely applicable for other ion-containing polymeric materials. This would be practical for not only self-healing but also for saving energy because the gasplastic capability allows polymers to mold at much lower temperatures in the presence of $\mathrm{CO}_{2}$. Further studies are currently underway in our laboratory and will be reported in due course.

\section{Methods}

Synthesis of PDMS-xNa. The PDMS- $x$ Na elastomer was prepared via carboxylation of PDMS, and then the carboxy groups were neutralized to some degree using sodium hydroxide (Supplementary Fig. 1). The PDMS containing amino groups at middle positions placed randomly along the backbone $\left(\mathrm{PDMS}-\mathrm{NH}_{2}\right)$ was synthesized via hydrolysis and condensation polymerization of diethoxydimethylsilane and 3-aminopropyldiethoxymethylsilane. The actual amino group's concentration in the PDMS- $\mathrm{NH}_{2}$ calculated from ${ }^{1} \mathrm{H}-\mathrm{NMR}$ spectrum was $\sim 2.7 \mathrm{~mol} \%$ (Supplementary Fig. 2a). The number average molecular weight and molecular weight distribution of the $\mathrm{PDMS}-\mathrm{NH}_{2}$ determined using polystyrene standards were 7300 and 1.56 , respectively. The PDMS- $\mathrm{NH}_{2}$ was reacted with succinic anhydride in dry chloroform. The actual concentration of the $\mathrm{COOH}$ group in PDMS-COOH was determined via neutralization titration with $\mathrm{NaOH}$ 
a

Self-healing of PDMS-75Na at room temperature

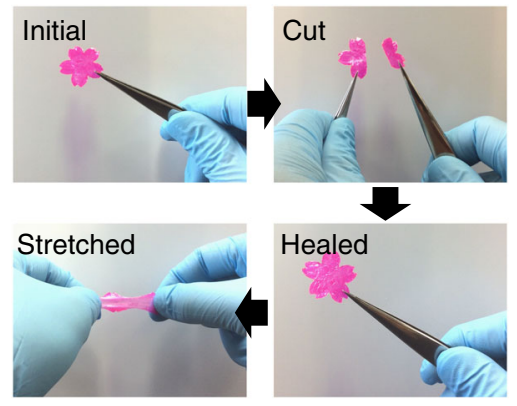

C

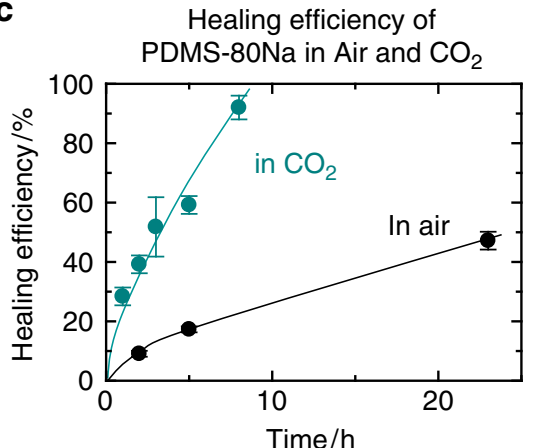

b

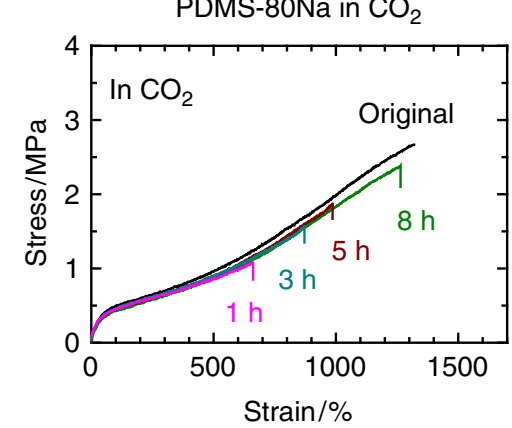

d

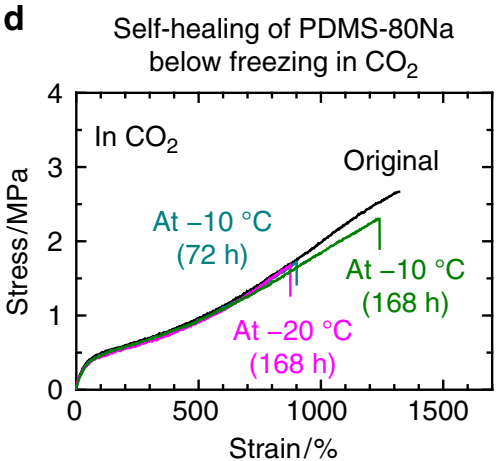

Fig. 4 Effect of $\mathrm{CO}_{2}$ on self-healing of PDMS-xNa. a Photograph of self-healing behavior of cherry blossom-shaped PDMS-75Na film at $26^{\circ} \mathrm{C}$. The film was painted pink. $\mathbf{b}$ Stress-strain curves of PDMS-80Na healed at $26^{\circ} \mathrm{C}$ in $\mathrm{CO}_{2}$. $\mathbf{~ T i m e ~ v a r i a t i o n ~ o f ~ h e a l i n g ~ e f f i c i e n c y ~ o f ~ P D M S - 8 0 N a ~ s t o r e d ~ a t ~} 26^{\circ} \mathrm{C}$ in air and in $\mathrm{CO}_{2}$. The error bars indicate standard deviations. d Stress-strain curves of PDMS-80Na healed at $-10^{\circ} \mathrm{C}$ and $-20^{\circ} \mathrm{C}$ in $\mathrm{CO}_{2}$

methanol solution, and the concentration of the $\mathrm{COOH}$ group was $3.8 \mathrm{~mol} \%$, which is higher than that of the $\mathrm{NH}_{2}$ group in the PDMS- $\mathrm{NH}_{2}$; this is because succinic anhydride was added to the hydroxy chain ends. An appropriate amount of $\mathrm{NaOH} /$ methanol solution was slowly added to a PDMS-COOH/THF solution (7 wt\%) under vigorous stirring. The mixture was then poured into a Teflon petri dish and dried at $35^{\circ} \mathrm{C}$ to form a cast film. The cast film was further dried at $35^{\circ} \mathrm{C}$ for more than 1 day in a vacuum. Upon neutralization, the intensity of the $\mathrm{COOH}$ carbonyl stretching band at $1716 \mathrm{~cm}^{-1}$ decreases, and a band indicating sodium carboxylate's stretching vibration is generated at $1586 \mathrm{~cm}^{-1}$ in the Fouriertransform infrared spectra (Supplementary Fig. 3).

Synchrotron SAXS measurements were performed using the BL-6A beamline at the Photon Factory of the High Energy Accelerator Research Organization (KEK) in Tsukuba, Japan. The X-ray wavelength $(\lambda)$ was $0.15 \mathrm{~nm}$. Stearic acid and silver behenate were used as SAXS detector calibration standards. The intensities were radially integrated, averaged, and redistributed to convert the pixel number to the corresponding scattering vector $q(q=(4 \pi / \lambda) \sin \theta)$ and produce a circularly averaged pattern.

Dynamic mechanical measurements were performed in tensile mode on a TA Instruments DMA Q800. Isothermal measurements were performed in each gas atmosphere at $1 \mathrm{~Hz}$ and $30^{\circ} \mathrm{C}$. The rectangular specimen dimensions were $10 \times$ $4.5 \times 0.4 \mathrm{~mm}$, and a strain of $0.5 \%$ was applied. Each gas (dry air, $\mathrm{N}_{2}$, and $\mathrm{CO}_{2}$ ) was flown into the sample chamber at a rate of $1.6 \mathrm{~L} \mathrm{~min}^{-1}$ during the measurements. Creep measurements were performed with a stress of $4 \mathrm{kPa}$.

The rheological properties were investigated in oscillatory shear on a parallelplate rheometer (AR-G2, TA instruments) with 8 -mm-diameter plates. The sample thickness was $\sim 0.4 \mathrm{~mm}$, and a strain of $0.5 \%$ was applied. A temperature sweep test was conducted at $1 \mathrm{~Hz}$ in the $-150^{\circ} \mathrm{C}$ to $150^{\circ} \mathrm{C}$ range at a heating rate of $3{ }^{\circ} \mathrm{C} \mathrm{min}{ }^{-1}$. Frequency sweep tests were performed in each gas atmosphere (dry air, $\mathrm{N}_{2}$, and $\mathrm{CO}_{2}$ ) within a dynamic range of $0.01-50 \mathrm{~Hz}$. Prior to the frequency sweep measurements, the dried PDMS-80Na film was exposed to an atmosphere of the relevant gas for $2 \mathrm{~h}$. The moisture-absorbed PDMS-80Na was measured in air. Prior to the measurement, a PDMS-80Na film was stored for 5 days in a glass desiccator maintained at $75 \%$ humidity and $28^{\circ} \mathrm{C}$. The weight of the film increased by $2 \%$ because of the moisture absorption.

The sample films' tensile stress-strain curves were collected using the AND Force Tester MCT-2150 at $27 \pm 1{ }^{\circ} \mathrm{C}$ under various gases (dry air, $\mathrm{N}_{2}$, and $\mathrm{CO}_{2}$ ). Dumbbell-shaped tensile bars, with dimensions of $25 \times 2.0 \times 0.4 \mathrm{~mm}$, were cut from the cast films. The initial gauge length was typically set to $11 \mathrm{~mm}$. Each measurement was performed at least thrice. The tensile stress $(\sigma)$ was calculated as $\sigma=F / S_{0}$, where $F$ is the loading force, and $S_{0}$ is the initial cross-sectional area of the sample film. The strain $(\varepsilon)$ under elongation was defined as the marker distance $(l)$ relative to the initial marker distance $\left(l_{0}\right)$ of the specimen, i.e., $\varepsilon=\left(l-l_{0}\right) / l_{0} \times$ $100 \%$. The increasing marker distance was monitored by a video camera.

Self-healing tests. The self-healing of scratches on the PDMS-70Na film surface was monitored by an optical microscope (Olympus BX53P). The film was scratched using a razor, and the depth of the scratch was controlled to $\sim 0.15 \mathrm{~mm}$ using a spacer. Scratched PDMS-70Na films were separately mounted on slide glass and stored at room temperature $\left(26^{\circ} \mathrm{C}\right)$ in either dry air or dry $\mathrm{CO}_{2}$ atmosphere. The strength recovery of the self-healed films was measured via tensile testing at $27 \pm$ $1{ }^{\circ} \mathrm{C}$. A PDMS-80Na film was scored, leaving a thickness of $12.5 \mu \mathrm{m}$, using a razor and a spacer to avoid completely cutting the film into two separate pieces. The cut faces were then placed in contact. The PDMS- $80 \mathrm{Na}$ films were stored at room temperature $\left(26^{\circ} \mathrm{C}\right)$ in either dry air or $\mathrm{CO}_{2}$ for different periods. The healed PDMS-80Na films were then stretched at $100 \mathrm{~mm} \mathrm{~min}^{-1}$ in air. The self-healing efficiency was calculated as the ratio between the tension energies required to break the original and self-healed materials. The tension energies were measured as the area below the stress-strain curve.

\section{Data availability}

The authors declare that the data supporting the findings of this study are available within the article and its Supplementary Information files or are available from the authors upon reasonable request.

Received: 27 November 2018 Accepted: 2 April 2019

Published online: 23 April 2019

\section{References}

1. Lieleg, O., Kayser, J., Brambilla, G., Cipelletti, L. \& Bausch, A. R. Slow dynamics and internal stress relaxation in bundled cytoskeletal networks. Nat. Mater. 10, 236-241 (2011).

2. Pritchard, R. H., Huang, Y. Y. S. \& Terentjev, E. M. Mechanics of biological networks: from the cell cytoskeleton to connective tissue. Soft Mater. 10, 1864-1884 (2014).

3. Porter, D. \& Vollrath, F. Nanoscale toughness of spider silk. Nano Today 2, 6-6 (2007). 
4. Keten, S., Xu, Z., Ihle, B. \& Buchler, M. J. Nanoconfinement controls stiffness, strength and mechanical toughness of $\beta$-sheet crystals in silk. Nat. Mater. 9, 359-367 (2010).

5. Wojtecki, R. J., Meador, M. A. \& Rowan, S. J. Using the dynamic bond to access macroscopically responsive structurally dynamic polymers. Nat. Mater. 10, 14-27 (2011)

6. Kim, S., Laschi, C. \& Trimmer, B. Soft robotics: a bioinspired evolution in robotics. Trends Biotechnol. 31, 287-294 (2013).

7. Li, J., Geng, L., Wang, G., Chu, H. \& Wei, H. Self-healable gels for use in wearable devices. Chem. Mater. 29, 8932-8952 (2017).

8. Huynh, T. P., Sonar, P. \& Haick, H. Advanced materials for use in soft selfhealing devices. Adv. Mater. 29, 1604973 (2017).

9. Cordier, P., Tournilhac, F., Soulie-Ziakovic, C. \& Leibler, L. Self-healing and thermoreversible rubber from supramolecular assembly. Nature 451, 977-980 (2008).

10. Chen, Y., Kushner, A. M., Williams, G. A. \& Guan, Z. Multiphase design of autonomic self-healing thermoplastic elastomers. Nat. Chem. 4, 467-472 (2012).

11. Oya, N., Ikezaki, T. \& Yoshie, N. A crystalline supramolecular polymer with self-healing capability at room temperature. Polym. J. 45, 955-961 (2013).

12. Sordo, F., Mougnier, S.-J., Loureiro, N., Tournilhac, F. \& Michaud, V. Design of self-healing supramolecular rubbers with a tunable number of chemical cross-links. Macromolecules 48, 4394-4402 (2015).

13. Wu, J., Cai, L.-H. \& Weitz, D. A. Tough self-healing elastomers by molecular enforced integration of covalent and reversible networks. Adv. Mater. 29, 1702616 (2017).

14. Cao, P.-F. et al. Superstretchable, self-healing polymeric elastomers with tunable properties. Adv. Funct. Mater. 28, 1800741 (2018).

15. Kang, J. et al. Tough and water-insensitive self-healing elastomer for robust electronic skin. Adv. Mater. 30, 1706846 (2018).

16. Mozhdehi, D., Ayala, S., Cromwell, O. R. \& Guan, Z. Self-healing multiphase polymers via dynamic metal-ligand interactions. J. Am. Chem. Soc. 136 16128-16131 (2014).

17. Li, C. H. et al. A highly stretchable autonomous self-healing elastomer. Nat. Chem. 8, 618-624 (2016).

18. Mei, J. F. et al. A highly stretchable and autonomous self-healing healing polymer based on combination of Pt...Pt and $\pi-\pi$ interactions. Macromol. Rapid Commun. 37, 1667-1675 (2016).

19. Wang, D.-P. et al. Distinct mechanical and self-healing properties in two polydimethylsiloxane coordination polymers with fine-tuned bond strength Inorg. Chem. 57, 3232-3242 (2018).

20. Das, A. et al. Ionic modification turns commercial rubber into a self-healing material. ACS Appl. Mater. Interfaces 7, 20623-20630 (2015).

21. Hohlbein, N., Shaaban, A., Bras, A. R., Pyckhout-Hintzen, W. \& Schmidt, A. M. Self-healing dynamic bond-based rubbers: understanding the mechanisms in ionomeric elastomer model systems. Phys. Chem. Chem. Phys. 17, 21005-21017 (2015).

22. Xu, C., Cao, L., Lin, B., Liang, X. \& Chen, Y. Design of self-healing supramolecular rubbers by introducing ionic cross-links into natural rubber via a controlled vulcanization. ACS Appl. Mater. Interfaces 8, 17728-17737 (2016).

23. Miwa, Y., Kurachi, J., Kohbara, Y. \& Kutsumizu, S. Dynamic ionic crosslinks enable high strength and ultrastretchability in a single elastomer. Commun. Chem. 1, 5 (2018).

24. Chen, X. et al. A thermally re-mendable cross-linked polymeric material. Science 295, 1698-1702 (2002).

25. Chen, X., Wudl, F., Mal, A. K., Shen, H. \& Nutt, S. R. New thermally remendable highly cross-linked polymeric materials. Macromolecules $\mathbf{3 6}$, 1802-1807 (2003).

26. Burattini, S. et al. A healable supramolecular polymer blend based on aromatic $\pi-\pi$ stacking and hydrogen-bonding interactions. J. Am. Chem. Soc. 132, 12051-12058 (2010).

27. Yoshie, N., Watanabe, M., Araki, H. \& Ishida, K. Thermo-responsive mending of polymers crosslinked by thermally reversible covalent bond: polymers from bisfuranic terminated poly(ethylene adipate) and tris-maleimide. Polym. Degrad. Stab. 95, 826-829 (2010).

28. Burnworth, M. et al. Optically healable supramolecular polymers. Nature $\mathbf{4 7 2}$, 334-337 (2011).

29. Montarnal, D., Capelot, M., Tournilhac, F. \& Leibler, L. Silica-like malleable materials from permanent organic networks. Science 334, 965-968 (2011).

30. Canadell, J., Goosens, H. \& Klumperman, B. Self-healing materials based on disulfide links. Macromolecules 44, 2536-2541 (2011).

31. Ying, H., Zhang, Y. \& Cheng, J. Dynamic urea bond for the design of reversible and self-healing polymers. Nat. Commun. 5, 3218 (2014).

32. Ji, S., Cao, W. \& Xu, H. Visible-light-induced self-healing diselenidecontaining polyurethane elastomer. Adv. Mater. 27, 7740-7745 (2015).

33. Neal, J. A., Mozhdehi, D. \& Guan, Z. Enhancing mechanical performance of a covalent self-healing material by sacrificial noncovalent bonds. J. Am. Chem. Soc. 137, 4846-4850 (2015).
34. Yanagisawa, Y., Nan, Y., Okuro, K. \& Aida, T. Mechanically robust, readily, repairable polymers via tailored noncovalent cross-linking. Science 359, 72-76 (2018).

35. Lai, J. C. et al. A rigid and healable polymer cross-linked by weak but abundant Zn(II)-carboxylate interactions. Nat. Commun. 9, 2725 (2018).

36. Kuo, A. C. M. Poly(dimethylsiloxane): Polymer Data Handbook (ed. Mark, J. E.) (Oxford University Press, New York 1999).

37. Yarusso, D. J. \& Cooper, S. L. Analysis of SAXS data from ionomer systems. Polymer 26, 371-378 (1985).

38. Van Alsten, J. G. Ionic and chain interdiffusion and interfacial strength development in ionomers of poly(ethylene-co-methacrylic acid). Macromolecules 29, 2163-2168 (1996).

39. Tierney, N. K. \& Register, R. A. The role of excess acid groups in the dynamics of ethylene-methacrylic acid ionomer melts. Macromolecules 35, 6284-6290 (2002).

40. Pandey, P. \& Chauhan, R. S. Membranes for gas separation. Prog. Polym. Sci. 26, 853-893 (2001)

41. Wind, J. D., Staudt-Bickel, C., Paul, D. R. \& Koros, W. J. The effects of crosslinking chemistry on $\mathrm{CO}_{2}$ plasticization of polyimide gas separation membranes. Ind. Eng. Chem. Res. 41, 6139-6148 (2002).

42. Maio, E. D., Iannace, S., Mensitieri, G. \& Nicolas, L. A predictive approach based on the Simha-Somcynsky free-volume theory for the effect of dissolved gas on viscosity and glass transition temperature of polymeric mixtures. $J$. Polym. Sci. Part B Polym. Phys. 44, 1863-1873 (2006).

43. Miwa, Y., Kondo, T. \& Kutsumizu, S. Sub-nanoscopic mapping of glass transition temperature around ionic multiplets in sodium-neutralized poly(ethylenerandom-methacrylic acid) ionomer. Macromolecules 46, 5232-5237 (2013).

44. Edvardsen, C. Water permeability and autogenous healing of cracks in concrete. ACI Mater. J. 96, 448-454 (1999).

45. Kwak, S.-Y. et al. Polymethacrylamide and carbon composites that grow, strengthen, and self-repair using ambient carbon dioxide fixation. Adv. Mater. 30, 1804037 (2018)

\section{Acknowledgements}

Beam time at PF-KEK provided by Programs 2016G627 and 2017G562 is acknowledged herein. Portion of these DFT calculations was performed at Research Center for Computational Science (RCCS), Okazaki. This research was financially supported by the Japan Society for the Promotion of Science (Grant-in-Aid for Young Scientists (B), $16 \mathrm{~K} 17958$ and Scientific Research (C), 16K05748); The Mazda Foundation (17kk-079); The Ogasawara Foundation for the Promotion of Science \& Engineering; and The Koshiyama Foundation.

\section{Author contributions}

Y.M. and S.K. planned and directed the project; Y.M., K.T., J.K., and T.U. conducted the experiments. Y.M. and K.T. analyzed the data; Y.M., S.K., and T.U. wrote the paper.

\section{Additional information}

Supplementary Information accompanies this paper at https://doi.org/10.1038/s41467 019-09826-2.

Competing interests: The authors declare no competing interests.

Reprints and permission information is available online at http://npg.nature.com/ reprintsandpermissions/

Journal peer review information: Nature Communications thanks Naoko Yoshie and the other anonymous reviewer(s) for their contribution to the peer review of this work. Peer reviewer reports are available.

Publisher's note: Springer Nature remains neutral with regard to jurisdictional claims in published maps and institutional affiliations.

Open Access This article is licensed under a Creative Commons Attribution 4.0 International License, which permits use, sharing, adaptation, distribution and reproduction in any medium or format, as long as you give appropriate credit to the original author(s) and the source, provide a link to the Creative Commons license, and indicate if changes were made. The images or other third party material in this article are included in the article's Creative Commons license, unless indicated otherwise in a credit line to the material. If material is not included in the article's Creative Commons license and your intended use is not permitted by statutory regulation or exceeds the permitted use, you will need to obtain permission directly from the copyright holder. To view a copy of this license, visit http://creativecommons.org/ licenses/by/4.0/

(C) The Author(s) 2019 